\title{
Tradición y dinámica editorial: hacia una renovadora visión crítica de la obra de Miguel de Cervantes. La labor editorial de la Academia del Hispanismo
}

\author{
Sergio ArLandis*
}

Afirmaba Vicente Gaos en su ya canónica obra Cervantes. Novelista, dramaturgo, poeta (1979) que el célebre autor barroco es, ante todo, «un proponedor inagotable, y para la comprensión de su obra nos brinda toda suerte de pistas: así las verdaderas como las falsas». Con tal definición casi podríamos trazar, dentro del inabarcable corpus bibliográfico que el conjunto de la obra cervantina ha generado a lo largo de los siglos, una primera y básica distinción: están quienes han elegido buscar lo «verdadero» cervantino en lo biográfico e historiográfico, para llegar a los fundamentos de su producción ficcional; y quienes, por otro lado, han pretendido alcanzar los fundamentos del «ficticio» Cervantes, ahondando en las posibilidades interpretativas de su obra, desde la ficción que destila su producción, el conjunto de sus personajes, hasta alcanzar, curiosamente, el grado de «verdad» que persiste y coordina, ideológica y estéticamente, su obra. Determinar cuál de estos dos senderos es el más fiable para llegar al pleno entendimiento de la obra cervantina depende, en todo caso, del lector y del crítico literario en cuestión, siempre y cuando su voluntad sea la de abordar la figura de Cervantes como personaje histórico o la de su obra como hecho históricoliterario en comunión y comunicación con otras manifestaciones artísticas.

Los caminos hermenéuticos son, en todo caso, tan extensos y cuantiosos que hasta nos parece pretencioso querer hacer un breve resumen sobre ello, pero lo que ya nos resulta más factible es hacer una valoración más concreta de cuáles son las principales vías por las que discurre la «tradición cervantista» en la actualidad y qué objetivos pretende, partiendo, eso sí, de la dualidad que mencionamos líneas atrás.

* HSP-University of Virginia. 
Quizás uno de los grandes inconvenientes que pueda tener un investigador a la hora de aproximarse críticamente a la obra de Cervantes sea el vasto caudal de estudios que se han ido acumulando indiscriminadamente. No toda obra publicada merece la atención que a veces se le ha concedido a libros, artículos y misceláneas que pueblan bibliotecas y estantes de librerías de modo sempiterno. Saber discernir qué clase de autores, publicaciones o asociaciones son realmente válidas para el enriquecimiento bibliográfico en torno al estudio de la obra Cervantes no siempre resulta fácil y, quizás, este hecho sea una de las más disuasorias amenazas para la incorporación de nuevos investigadores y lectores. Siempre existen referentes que no podemos dejar de lado, como Américo Castro, Joaquín Casalduero, Jean Canavaggio y tantos otros que injustamente no cito y con los que siempre hay que contar para completar los primeros pasos de un estudio serio y riguroso sobre la obra de Cervantes. Pero estos autores son, en verdad, los resortes de una tradición crítica cervantista que, por norma y necesidad científica, ha progresado hacia nuevos campos de investigación, ampliando o restringiendo aquellos temas y motivos que, en épocas pasadas, se habían apuntado como propiamente «cervantinos». De nuevo, pues, los insondables caminos de lo real y lo aparente: la obra que se reviste de complicidad ambigua frente a su lector.

Obviamente, dentro de esa tradición cervantista cabe destacar, en la actualidad, la importante labor de la revista Anales cervantinos (editada por el Instituto Miguel de Cervantes del CSIC) que, tras su fundación, con la Asamblea Internacional Cervantina celebrada en los años 1947 y 1948 (y después de superar un largo silencio de diez años iniciado en 1962), ha enriquecido, mediante la publicación de importantes artículos, el estudio de la obra de nuestro autor. También merece especial atención la Asociación de Cervantistas, fundada en 1988 y localizada en Alcalá de Henares (junto con el Centro de Estudios Cervantinos), cuyo cometido principal está siendo el de la convocatoria de interesantes congresos en torno a la figura de Miguel de Cervantes cada tres años y la posterior publicación de sus Actas, donde se combinan estudios de autores de primera fila con interesantes artículos de jóvenes filólogos que aportan nuevas y renovadas visiones de aspectos más concretos de la obra cervantina. Por supuesto, también podemos encontrar las importantísimas aportaciones del Cervantes Society of America, con la impecable publicación de su Bulletin y el imprescindible Anuario Bibliográfico Cervantino. Además - y sin que eso suene, en cierta manera, a modo de conclusión, pues se han quedado por el camino demasiados referentes-, cabe añadir la creciente relevancia que el grupo de investigación dirigido por Diego Martínez Torrón, Andalucía Literaria, viene obteniendo progresivamente, con interesantes monográficos sobre el autor áureo.

Pero de todos estos caminos por los que discurre la tradición crítica cervantista queremos hacer una detenida consideración y valoración de toda una línea editorial que está creciendo y cimentándose en torno a una coherente visión de su propuesta metodológica y de su objeto de estudio. Es, quizás, una de las más fuertes y fiables apuestas para el acercamiento crítico al 
célebre escritor barroco y pasa por constituir - dentro de la pluralidad de posibilidades que actualmente ofrece - todo un referente para el presente y un imprescindible recurso bibliográfico para el futuro. Nos referimos a las publicaciones que desde la editorial Academia del Hispanismo se vienen realizando periódicamente, aunque muchos son los aspectos que dentro de esta afirmación cabría matizar y precisar, a pesar de la pasmosa coherencia que organiza, estructura y determina el amplio serial de publicaciones que vienen ofreciendo a la agradecida tradición cervantista.

En 2003 Jesús G. Maestro (uno de los principales artífices del importante proyecto editorial), publicaba, bajo categoría de editor, el número $\mathrm{V}$ de Theatralia. Revista de Poética del Teatro (Mirabel Editorial), con el subtítulo de El teatro de Cervantes ante el IV Centenario de la edición del Quijote 1605-2005. Comenzaba así la difícil aventura de rescatar, para la causa la figura del Cervantes dramaturgo: quizás del Cervantes menos «universal» ( su faceta como dramaturgo no fue, precisamente, la más exitosa en vida del autor), pero no por ello menos relevante o «menor». Este volumen, resultado del V Congreso Internacional de Theatralia en la Università degli Studi di Firenze, no solo servía de pistoletazo frente a la conmemoración del Quijote, sino que, desde sus páginas iniciales Jesús G. Maestro dejaba bien definido y claro qué pautas críticas regirían el resto de obras en torno a Cervantes que, a partir de ahí, fueron llegando. El texto, como telón de fondo, se titula $E l$ triunfo de la heterodoxia. El teatro de Cervantes y la literatura europea: y en él encontramos la reivindicación de un Cervantes en consonancia con una época en plena crisis ideológica. Precisamente en los períodos de crisis surge la renovadora voz de una estética disidente que anuncia, desde su ruptura, esa desintegración de los valores que la sustentan; es ahí donde cabría encuadrar la obra teatral de Cervantes y no como resorte comparativo frente al exitoso espectáculo teatral lopesco. En este sentido, Maestro abre la vía de una lectura del teatro cervantino (que podemos hacer extensible a toda su obra), que reivindica como «teatro para un público extemporáneo». Seguidamente critica - siempre con argumentos, elegantes pero disidentes - la poca consideración que esta faceta dramaturga de Cervantes ha tenido, incluso en los casos en los que se ha trabajado en torno al propio teatro cervantino. Sucesivamente apunta a la teoría comparatista como metodología que, en este caso, mejores resultados interpretativos puede ofrecer (por ejemplo, la obra de Cervantes dentro de una dinámica estética e ideológica europea $\mathrm{y}$, en consecuencia, constatar, con ello, la tremenda originalidad de su propio planteamiento) para, finalmente, establecer nexos de unión diacrónicos con el teatro grecolatino hasta llegar a los cimientos de la tradición dramatúrgica en los que fundamentó su concepto de la obra teatral. Así - y constatando qué grado de relación tuvo Cervantes con la tradición clásica- se adentra en la comparación de su producción teatral con la de sus contemporáneos dando, como resultado, un Cervantes «moderno», en los umbrales del decisivo cambio del pensamiento humano (antropocentrismo, desarrollo científico, racionalismo). Tal trayecto crítico propuesto - y expuesto, como se ve, a través de su propio texto- nos 
acaba llevando hasta la orilla de un principio fundamental: «leer a Cervantes desde el cervantismo, endogámicamente, no nos permitirá fácilmente ver nada nuevo más allá del cervantismo». A partir de ahí surge el interés por mostrar - desde el riguroso estudio de las fuentes y de los textos literarios- un Cervantes «precursor del mundo contemporáneo, liberal, ilustrado y laico». Dar forma, en definitiva, a una lectura plural, ensanchadora, exhaustiva de aquellos factores que hacen de la obra de Cervantes un emblema cultural, estético e ideológico puramente atemporal.

Por tanto, estamos ante una línea de trabajo tan definida como sorprendentemente unitaria y coherente: por un lado, el estudio de Cervantes desde la perspectiva de la Historia de la Literatura (que propone encuadrar una obra dentro de una corriente estética); posteriormente, valorar la obra literaria acorde con los fundamentos metodológicos interpretativos con el fin de no sobreponer la crítica de un texto al propio texto literario analizado por encima de cualquier aspecto puramente biográfico; y, por último, una revisión, estimación y juicio de la historia de la crítica de la obra cervantina.

El volumen, por otro lado, viene firmado por un amplio y valioso número de reconocidos estudiosos de la materia: primero Christina Karageorgou, Cory A. Reed y Carmen González Vázquez, estudian a través de sus artículos la relación del teatro de Cervantes con la cultura grecolatina; Aurora Egido, Frederick A. de Armas, Simone Pinet, Marco Lombarda, David Castillo y Nicholas Spadaccini hacen lo propio con los desiguales contextos renacentista y barroco. En sendos capítulos, pues, se valora la obra cervantina desde la herencia y la diferencia de Cervantes con respecto a su época y a la tradición que lo formó. Sin embargo, el apartado que abre la recepción de la obra cervantina en el período ilustrado y romántico (en el que encontramos los artículos de Minh Sawhney, Emilio Martínez Mata y Urszula Aszyk), ya nos muestra una visión diferente de su obra: la proyección de una ideología llevada a los terrenos de lo estético, tanto en la producción como en la recepción e, incluso, por el uso de tal legado literario. Finalmente, los artículos de Marco Cipollini, Lola Josa, Carmen Becerra, Chiara Essen y Susan L. Fischer nos revelan la importancia de la obra teatral de Cervantes en la evolución y desarrollo de la dramaturgia española del siglo XX y de cómo ese teatro (que se juzgó tan equivocadamente desde su fracasada puesta en escena en la época) acabó influyendo notablemente la obra de autores como Lorca, Casona, Torrente Ballester, Camus o Somoza.

Tras una visión de la obra teatral de Cervantes en la historia de la literatura, el libro se adentra en la exhaustiva lectura de ciertas obras y en las claves estéticas que las fundamentan: gran valor tienen los artículos dedicados a la Numancia y su carácter trágico, firmados por Georges Güntert, Eric C. Graf y Heinz-Peter Endress. Por supuesto, los entremeses gozan de su justa atención con artículos como los de Catalina Buezo Canalejo, Vicente Pérez de León y Joseph V. Ricacito. Así hasta dar con los estudios más generales en torno a las comedias cervantinas que tan rigurosamente han analizado Anthony Close, Edward H. Friedman, Aldo Ruffinatto, Paul Lewis-Smith, José 
Manuel Trabado y Aurelio González Pérez. Idéntico planteamiento podemos hacer si valoramos el resto de autores que campan, con los trabajos dedicados a la producción no teatral de Cervantes (pero con el nexo de unión del desentrañamiento de una "visión de mundo»), entre los que encontramos a María Roca, Katerina Vaiopoulos y Agapita Jurado. El volumen lo cierra, en síntesis plenaria, uno de los autores que como un pionero más ha reivindicado la figura de Cervantes como dramaturgo (aunque la considera una «obra en ciernes»): Jean Canavaggio, quien realiza un recorrido valorativo, después de cumplirse 25 años de la publicación de su innovador Cervantès dramaturge. En las páginas finales del volumen encontramos, además, una amplísima y valiosa selección bibliográfica de las principales ediciones del teatro de Cervantes y de los estudios críticos que ha suscitado.

Sin duda este volumen dedicado al teatro ha abierto, con gran novedad y fuerza, todo un serial de publicaciones fundamentadas, precisamente, en aquellos aspectos que desde el citado monográfico se reforzaban y se pregonaban como principios básicos: el no seguir la inercia de los estudios cervantinos y aportar, en consecuencia, nuevos estudios con otros fines interpretativos, con otras perspectivas (incluso transversales e interdisciplinares) y valientes juicios de valor cargados de novedad y renovado interés.

En el año 2004 se creó y salió a la luz pública el primer número del Anuario de Estudios Cervantinos (Mirabel Editorial), cuyos directores fueron Eduardo Urbina y Jesús G. Maestro, apoyados por un Comité Científico de primer nivel internacional. Como puede suponerse el número inaugural estaba dedicado íntegramente a la conmemoración del IV Centenario del Quijote. Y cabe examinar si aquellos propósitos apuntados en aquel volumen de Theatralia se confirmaban un año más tarde. Su estructura no deja lugar a dudas: tras una visión panorámica e histórica del Quijote entre sus contemporáneos, firmada por Anthony Close, pronto nos encontrábamos con un segundo capítulo dedicado a la recepción del célebre texto cervantino (con artículos de Edward Friedman, Georges Güntert y María Jesús Barsanti) y la evolución de la novela moderna. Un tercer apartado — siguiendo la teoría metodológica comparatista - trata del Quijote en la literatura comparada y las bellas artes (con artículos de Rosa Navarro Durán, Frederick A. De Armas y David Boruchoff) que, por otro lado, acabará siendo uno de los aspectos más sobresalientes de toda la línea editorial en conjunto. De ahí — cuarto apartado - pasamos a un estudio de los fundamentos estéticos e ideológicos que impregnan el Quijote, donde tenemos textos de Heinrich Merkl, Hilaire Kallendorf y Martha García, donde anticipa aquello que, años más tarde, ha sido un provechoso estudio sobre la figura de la mujer en la obra de Cervantes. Finalmente, la recopilación que realiza Eduardo Urbina de una completa bibliografía cervantina entre el 2003 y el 2004 resulta, cuanto menos, esclarecedora y altamente útil para el investigador.

Pero fue el año 2005 el que, definitivamente, confirmó editorialmente la dinámica de publicaciones sobre los textos cervantinos: se publicó el segundo número del Anuario de Estudios Cervantinos (Mirabel Editores), bajo el epí- 
grafe Don Quijote y la crítica literaria contemporánea. Se buscaba, con esta publicación, llevar a cabo una revisión de la obra a través de la metodología comparatista propuesta por, entre otros, Edward E. Riley. Y, desde luego, los artículos firmados por José María Ruano de la Haza, Ana León Manzanero, Barbara Simerka y Christopher Weimer junto a Francisco Vivar dan una visión amplia y detallada de cómo la célebre novela áurea ha sido todo un referente estético en otros ámbitos culturales, ideológicos, históricos y geográficos. Le siguen los interesantes trabajos de Martha García, Juan Diego Vila y Minh Sawhney centrados en la imagen de la mujer en el Quijote, por cuanto constituyen máscaras actorales que permiten ver, con mayor claridad, la «otredad» del discurso cervantino, la relatividad de su «realidad crítica» y conducen a un debate profundo de los resortes ideológico-culturales de una sociedad en plena crisis. Y es precisamente esa misma vía de interpretación la que nos lleva al apartado final, con textos de Georges Güntert, Jacques Joset y Carmen García de la Rasilla, pues en sus estudios queda patente la relación tan significativa que el Quijote guarda con el desarrollo de otras manifestaciones, fruto también de profundas crisis del pensamiento humano a nivel europeo. Finalmente, la bibliografía cervantina recogida por Eduardo Urbina correspondiente al año 2005, vuelve a ser indispensable y recurrente desde entonces en todos los sucesivos números del Anuario.

Tras un año de cambios internos, cuyo resultado final fue el silencio editorial, salió publicado el tercer número en 2007 del Anuario de Estudios Cervantinos (Academia del Hispanismo), precedido por el epígrafe Cervantes entre dos Siglos de Oro: de La Galatea al Persiles, coeditado, nuevamente, por Eduardo Urbina y Jesús G. Maestro. Como si se tratara poliédricamente la figura de Cervantes, el volumen realiza un amplio recorrido sobre toda su obra, siempre tratando de exponer los tres principios básicos de su línea editorial, aunque, en este caso, centrándose en el estudio de sus fundamentos estético-temáticos y en la recepción de la obra de Cervantes, tanto en un nivel diacrónico o como en el más sincrónico, pero eludiendo las fronteras territoriales y proyectando la figura de Cervantes más allá del corto margen del territorio nacional y de la concreta época barroca. Así, el texto de Rachel Schimdt — que abre el volumen — profundiza, a través de las máscaras actorales de los pastores y los esquemas alegóricos, en la vinculación que existe entre La Galatea de Cervantes y la Lucinde de Friedrich Schlegel; de igual modo Alfredo Baras, María de los Ángeles González Briz y Marcella Trambaioli se interesan por los diferentes aspectos de la obra poética y teatral de Cervantes que, de un modo u otro, han atravesado el denso margen de tiempo; no en vano, sus respectivos estudios abarcan desde el siglo XVI hasta el XX. Posteriormente se analiza, con cuidado detenimiento, la relación de Cervantes con la novela: podemos encontrar artículos de un calado ciertamente significativo, como el que firma Jean Canavaggio, o una nueva aportación a ese debate abierto entre Lope y Cervantes que realiza Rosa Navarro Durán. Del mismo modo, el estudio de Michael Schinasi nos lleva a los albores del cambio de rumbo que experimentó la novela durante el siglo XIX y cómo en ese telón 
de cambio surge, de nuevo, la imagen de Cervantes como un narrador eficaz y aventajado. El cuarto apartado nos acerca al estudio — siempre inagotabledel Quijote, aunque esta vez tratando la imagen del Ingenioso Hidalgo desde la pluralidad de sus diferentes manifestaciones literarias: así encontramos los interesantes estudios de Gustavo Bueno, William H. Clamurro, David F. Arranz, Fernando González Moreno, Javier Irigoyen-García y Marcelina J. Suárez. Así hasta dar con el profundo trabajo de Francisco Javier Escobar sobre los Trabajos de Persiles y Segismunda, con toda una teoría sobre la transmutación del cuerpo en imagen y símbolo de un ideal; un paso que, a pesar de ser, en esencia, un modo de aspirar hacia el equilibrio interior acaba siendo, en muchos casos, el paso definitivo para la perdición y la locura en la obra cervantina.

En el año 2008 se ha publicado el que es, hasta la fecha, el cuarto número del Anuario de Estudios Cervantinos (Academia del Hispanismo), titulado Del texto del Quijote a la Literatura Comparada y las Bellas Artes. Un volumen que, como veremos, va a la par de las publicaciones que la editorial va ofreciendo paralelamente por otros cauces. No obstante, vuelven a quedar bien patentes los principios rectores de la colección: la dialéctica entre culturas, estéticas y épocas devuelve una visión mucho más amplia, rica y real de lo que Cervantes y su obra han sido (y son) dentro del amplio marco de la cultura occidental y, en concreto, dentro de las manifestaciones artísticas más plurales coetáneas o no. Con este objetivo abre el volumen el trabajo de Fernando González Moreno y Eduardo Urbina al hacer especial hincapié en un estudio de la iconografía textual del Quijote como elemento determinante a la hora de confeccionar unos rasgos y unas identidades figurativas de todos los personajes de la obra: un hecho que acaba marcando el imaginario colectivo hasta guiarlo hacia la estereotipación de dichas figuras. No en vano - y tras el paso previo por el trabajo de Florencio Sevilla dedicado a los aspectos formales en la confección de la primera edición del Quijote - el tercer apartado se dedica al análisis de los personajes que pueblan la obra cervantina: hacia la construcción de sus respectivas identidades y sus interpretaciones posibles, como se evidencia a través de los estudios de Jaime Fernández, Ruth Fine, Iván Fernández, Bénédicte Torres y José María Ferri. El cuarto apartado del volumen presta su atención a las Novelas Ejemplares y a los entremeses, tratando de enarbolar un nexo de unión dentro de esa visión plural de Cervantes y con el ánimo de abrir el interés hacia otras de sus obras, como proponen los estudios de Jorge García, Paul Lewis-Smith y María Dolores Morcillo, respectivamente. Finalmente cierra esta cuarta entrega del Anuario un amplio apartado dedicado a la figura de Cervantes desde el punto de vista de la Literatura Comparada, es decir, como objeto de una disciplina que arroja una nueva visión del hecho literario y sus resultados; por ejemplo, Juan José Pastor nos avanza un nuevo aspecto (inclinado hacia una visión más contemporánea) de sus ya conocidos estudios en torno a la relación del Quijote con la música; Franco Quinziano nos ofrece una interesante revisión de la recepción del Quijote en la Italia del siglo XVIII, mientras que Mercedes Rodríguez Pequeño 
nos hace una valoración general de Cervantes como objeto de análisis de la teoría literaria, así como Barbara Simerka y Christopher Weimer nos acercan a una visión comparativa entre el Quijote de Cervantes y la película Stranger than Fiction (2006) escrita por Zach Helm; y Francisco Vivar revisa la plural aplicación del término «necesidad» en autores o personajes como Maquiavelo, Lázaro de Tormes, Montaigne y el propio Cervantes.

A la par que se publicaba el segundo número del Anuario, la editorial - por entonces Mirabel Editores- creaba la Colección Biblioteca Miguel de Cervantes bajo la impecable dirección de Jesús G. Maestro. Inauguraba tal colección el libro que coordinaron a la par Eduardo Urbina y Jesús G. Maestro, titulado Don Quixote illustrated: Textual Images and Visual Readings. Iconografía del Quijote (Mirabel Editorial), galardonado con el Premio Internacional Cátedra Cervantes-Grupo Santander. De nuevo el interés por el estudio global nos lleva a la valoración de un aspecto tan periférico y externo dentro del diseño de un libro, pero decisivo a la hora de interpretar, concebir y comprender cómo se ha ido asimilando y aprehendiendo la célebre obra de Cervantes a lo largo de la ancha geografía occidental y de la historia. Si partimos de la consideración inapelable de que la relación entre las artes plásticas y la escritura cervantina apenas había sido tratada (y relacionada) hasta la fecha, excepción hecha de algunas célebres exposiciones de claro dominio visual sobre el textual, pronto entendemos la importancia de un libro como este pues arroja un importante balance de aquellos aspectos que ayudaron a concebir el arquetipo quijotesco y sus adyacentes ficcionales y, en consecuencia, a la asimilación de aquellos aspectos que relacionaba la obra cervantina con las inclinaciones estéticas del ser humano.

Ciertamente importante nos parece la división que realiza Eduardo Urbina en el primer capítulo del libro, en el que, tras analizar el amplio corpus de la iconografía del Quijote, la divide y secciona en cinco grandes períodos: de 1605 a 1640, donde prima la ausencia de ilustraciones; de 1640 a 1725, donde pueden encontrarse ya las primeras ilustraciones; de 1725 a 1800, período en el que surgen imágenes de marcado clasicismo; entre 1800 y 1880, donde el carácter romántico acabó dando una imagen muy característica de la figura quijotesca; y, por último, entre 1880 y 2005, donde Don Quijote se convierte en una suerte de «maniquí» simbólico al el que los autores más emblemáticos vuelven sus ojos, quizás como testaferro de una sensibilidad moderna herida por su propia crisis de identidad y el resquebrajamiento de todo un sistema de valores morales e ideológicos puestos, seriamente, en duda. Por su parte Rachel Schmidt hace una valoración mucho más centrada en un período concreto: el III Centenario del Quijote, celebrado en 1905, y las particularidades estéticas que esto trajo consigo en la representación del «caballero de la triste figura». Patrick Lenaghan, lejos de fijarse en una época, se centra en algunos pasajes de la obra cervantina y cómo se fueron plasmando pictóricamente y la carga interpretativa que este hecho conllevaba. El estudio de Stephen Miller, en cambio, toma como referente la personal visión de dos autores como Salvador Dalí y Gustavo Doré como lectores y recreadores del Quijote. Igual- 
mente curioso nos parece el artículo triplemente firmado por Isidro Sánchez, Esther Almarcha y Óscar Fernández Olalde donde se analizan los diferentes ephemera (o dibujos de claro carácter efímero, temporal y casi panfletario o circunstancial) en cuanto que constituyen un valioso material para coleccionistas y también porque arrojan periféricas informaciones en torno a cómo un período (o una ideología) determinado asimilaba la figura del Quijote. Mientras que los dos últimos trabajos publicados en el libro tienen una doble intención muy concreta: por un lado, Enrique Mallén nos traslada al cubismo de Picasso como antesala de una ruptura estética de los principios rectores de un planteamiento racional, así, la imagen del personaje cervantino vuelve a ser adalid de tal transformación que es, a fin de cuentas, su propia metamorfosis plástica en la nueva concepción de la invidualidad contemporánea. Por otro lado, Richard Furuta, Jie Deng, Carlos Monroy y Neal Audenaert nos abren el limitado espacio de visión de lo que un estudio en torno a la iconografía del Quijote supone (y supondrá) en cuanto apertura de campos intelectivos para su interpretación. Tal objetivo — nos informan — se viene gestando a través de un ambicioso proyecto en Texas A\&M University (auténtica referencia en el mundo académico internacional en el estudio de la obra cervantina, junto a la Universidad de Castilla-La Mancha), institución que, sin duda, se convierte, desde entonces, en parte importante en el desarrollo del fomento de la figura de Cervantes y donde la presencia de Eduardo Urbina se convierte en primordial y determinante.

El mismo año de 2005 aparecía el libro Cuentos y episodios del Persiles de La isla bárbara a una apoteosis del amor humano (Mirabel Editorial) de Stanislav Zimic que, por otro lado, ya es sobradamente conocido por ser autor de uno de los libros más importantes sobre la obra cervantina - El teatro de Cervantes (1992) - y de numerosos artículos de gran interés y trascendencia. Precisamente su singular y coherente visión de Cervantes ha propiciado que Zimic reúna un buen número de sus artículos en un solo volumen sin que se puedan apreciar desequilibrios internos, contradicciones, cambios de parecer (lógicos, conforme se avanza en el tiempo y en la investigación) o trabajos muy desiguales: parte de un análisis y revisión de la novela bizantina (sobre todo de sus rasgos más comunes como subgénero) hasta llegar al análisis de los episodios y relatos que emergen a lo largo de Los Trabajos de Persiles y Segismunda. El estudio de Zimic acaba desentrañando todas las claves tipológicas que ayudan a construir «a este complejo protagonista del Persiles en algunos de sus aspectos particulares y en su conjunto, con resultados a menudo muy diferentes de los conseguidos por otros lectores». Pues si, por un lado, Zimic se había propuesto justificar y explicar por qué el Persiles cabía identificarlo como novela bizantina (sus claves genéricas, su deudas con el modelo); por otro lado, en cambio, el estudio deriva en un análisis de cómo se construye, a través de ese molde clásico, una nueva identidad movida por la concreta «visión de mundo» de Cervantes, consecuente hasta el mismo umbral de su muerte: ¿estamos, pues, ante una obra de profundo calado biográfico si consideramos que ya en 1613 había anunciado su aparición? Pensamos que, 
en este sentido, el libro de Zimic no está diseñado sobre la única base de la determinación de unas claves constatables del Persiles, sino que, sobre todo, está clamando por establecer un diálogo abierto con el lector, quizás pensando que en el umbral de dicho intercambio de pareceres puede radicar el auténtico valor literario de una obra que aún sigue abriendo un sinfín de interrogantes sobre las razones de su escritura.

Como ya dijimos, el año 2006 fue un período de transición y de merecido descanso, tras haber pasado el intenso año de la IV conmemoración del Quijote. Aquel Mirabel Ediciones pasaba a llamarse definitivamente Editorial Academia del Hispanismo. Se inauguraba tal cambio con la publicación, en 2007, de Cervantes. Música y Poesía. El hecho musical en el pensamiento lírico cervantino, de Juan José Pastor Comín, como resultado de un proyecto de investigación patrocinado por la Cátedra Cervantes (Universidad de Castilla-La Mancha). El libro, además de contar con un autor especializado en las diferentes vinculaciones entre la obra de Cervantes y la música, fue merecidamente galardonado con el Premio Internacional Cátedra CervantesGrupo Santander. Siguiendo la estela editorial, la obra de Pastor Comín lleva a cabo una exhaustiva reflexión «sobre la relevancia del hecho musical en la escritura de Cervantes» y constata cómo implica un rico horizonte estético que impregna su poco estudiada obra poética; de nuevo, el análisis plural junto con la novedad del planteamiento hermenéutico hacen de esta obra un auténtico punto de inflexión dentro del estudio de la obra poética de Cervantes, pues como recuerda el propio autor: «La carencia de una obra cervantina a modo de rimas o cancionero y la dispersión y diseminación de sus composiciones líricas han hecho difícil el análisis de su producción poética; sin embargo es precisamente desde esa condición de textos integrados en otros contextos literarios - dramáticos y narrativos - desde donde deben recibir una interpretación y un primer intento de evaluación». Tal empresa la cumple brillantemente Pastor Comín y de su estudio cabe preguntarse hasta qué punto esta perspectiva tan bien diseñada (a modo de pentagrama amplio y perfectamente estructurado) de sus composiciones poéticas no podría ser, también, motivo de análisis del resto de sus obras en cuanto a la armonía escénica, por ejemplo, al equilibrio (o desequilibrio cuando se trata de algún pasaje puramente irónico) de personajes en escena, de diálogos, de temas o del excelente ritmo de sus obras en prosa.

Ex aequo al libro de Pastor Comín se publica el de Giuseppe Grilli, titulado Sobre el primer Quijote, y galardonado con un renovado I Premio Internacional Cátedra Cervantes-Grupo Santander (que hasta la fecha conoce un total de tres entregas), concedido en el año 2006. Desde sus palabras iniciales se nos anuncia que el libro supone una nueva visión del Quijote incluso para el propio autor, quien advierte al lector que, ante todo, va ser cómplice de una «interpretación personal de la obra maestra». En consonancia con las posteriores publicaciones de Jesús G. Maestro y Georges Güntert, Giuseppe Grilli pone en liza la visión de un Cervantes en una época llena de contradicciones, requiebros del intelecto y grandes avances. A partir de tal determinación, Grilli 
se propone la difícil tarea de sistematizar la novedad que el Quijote supuso en los albores de una crisis de pensamiento y una revisión de los fundamentos estéticos todavía heredados del Renacimiento. Pero más allá de tal propósito Grilli no duda en determinar que la obra cervantina fue en verdad - y tras su novedosa articulación en forma de novela, coherente y estructurada- un lugar «propicio para entender el mundo, si es que este puede entenderse, y hasta donde puede llegar la comprensión humana, es a mi manera de ver, el reto del libro de 1605». Y entre tanta afirmación de una «visión de mundo» un inquietante trasfondo paradójico se acaba convirtiendo en «la base de la novedad cervantina: el libro, para existir, se niega. Don Quijote, para sobrevivir como eje, se exilia de la mayor parte de su biografía». Porque Grilli, con su libro, confirma el debate con el que abríamos el presente texto: ¿hasta qué punto Miguel de Cervantes dejó impresa su fantasmagórica presencia en la voz narradora del libro?, ¿de qué modo probar el calado biográfico en un libro que borra, precisamente, cualquier atisbo de identidad y la suplanta por imágenes concatenadas de un delirio permanente? Es ese, exactamente, el debate que la ilustre obra de Cervantes abre con maestría hasta llevarnos a una visión de la realidad novelada y una novela sobre la realidad donde nos insertemos como individuos.

Y si volvemos a hacer hincapié en la pasmosa coherencia editorial, también durante el año 2007 salió publicado el libro de Jesús G. Maestro titulado Las ascuas del Imperio. Crítica de las Novelas Ejemplares de Cervantes desde el materialismo filosófico. Es, sin duda, una de las obras más importantes publicadas en los últimos años sobre la obra del autor barroco. Muy en sintonía con las teorías de Grilli (con ese telón de fondo llamado E. C. Riley) y de Georges Güntert, a quien significativamente le dedica el libro, Jesús G. Maestro lleva a cabo una investigación novedosa y sólida en la que se nos apunta la teoría de que los conocimientos históricos, filosóficos, teóricos, textuales y extratextuales deben ser importantes contextos que envuelven la obra literaria y, por tanto, cabe tenerlos presentes en todo momento, dentro de una mirada integradora, coherente y consecuente con el período histórico de la obra analizada, con las claves estéticas internas y externas que la sustentan y con su recepción no sólo como lectura sino también como parte importante dentro de la sucesiva evolución del pensamiento y de sus manifestaciones artísticas. Volvemos, nuevamente, a aquellos objetivos marcados al comienzo de tan titánica aventura editorial.

El libro, por otro lado, no peca de conformismo a la hora de abordar el estudio de las Novelas Ejemplares. El tono marcadamente dialéctico que lo sustenta lo hace ciertamente polémico en el mejor sentido de la palabra: frente a la estereotipada consideración de Cervantes como erasmista el autor no duda en ir, poco a poco, desgajando los pilares ideológicos que a través de los textos se pueden cotejar sin falsear - o acaso manipular - en beneficio de tales consideraciones ya vetustas. Maestro ve mucho más cercano a Cervantes con respecto a las teorías racionalistas y ateístas de Baruj Spinoza, que de Erasmo o de los postulados de la Contrarreforma, tan relativamente coincidentes en el 
tiempo. El objetivo no es otro que el de demostrar lo poco ortodoxo que fue Cervantes en su época y cómo ese carácter, crítico y descreído, ha hecho del autor áureo todo un icono cultural dentro de la modernidad. Maestro apunta, en consecuencia, que la auténtica repercusión de su lectura no estribaba tanto en la cantidad de lectores en sí (éxito editorial) sino en la hondura de su pensamiento, producto de una identidad cultural de que se rebeló endogámicamente: Cervantes queda, pues, situado en el decisivo paso hacia una sociedad marcada por el ateísmo y el triunfo (aunque efímero y también esquizofrénico en cierto modo) del pensamiento antropológico y de la Razón. Pero Cervantes es también el narrador de la derrota misma de estos valores y por ello juega - recordemos aquellas iniciales palabras de Gaos - al despiste, al engaño, a la burla y a la confusión: las falsas pistas que borran la auténtica identidad del autor y nos devuelven la ficticia máscara del narrador porque, desde la base de su concepción de la realidad, «todo lo que existe está a disposición del ser humano y puede ser manipulado por él».

Con el libro de Iole Scamuzzi, titulado Encantamiento y transfiguración. Don Quijote en el melodrama italiano entre los siglos XVII y XVIII, también publicado en el 2007 (y al que se añade, por primera vez, una numeración propia de la colección), volvemos a los estudios comparados, tanto a través del tiempo como mediante la pluralidad que ofrece el cambio de espacios territoriales y la teoría de la recepción que estos estudios conllevan. La obra de Scamuzzi trabaja sobre la relación entre Cervantes y la música, pero sobre todo sobre el recorrido del Quijote en Italia, bien como texto o como objeto de estudio en sí mismo. Para ello el autor reconoce basarse en las traducciones e imitaciones italianas de la novela pero, de manera más particular, realiza un denso recorrido en torno a la presencia del personaje cervantino en el teatro con música italiano, tomando como referencia los libretos principalmente y solo en casos muy concretos, las partituras. Sin embargo, este trabajo de Scamuzzi, bien estructurado y argumentado de principio a fin, no tiene más que rendirse a la evidencia: la imposibilidad de poder cotejar y catalogar los textos de aquella época ya que «sólo es posible abarcar obras cuya existencia y autor conocemos», por lo que sus logros — que son muchos y ciertamente enriquecedores - pasan por ser insuficientes y parciales, pero tantos como para arrojar una primera valoración: «este trabajo se articula en tres partes que corresponden a las distintas formas que asume don Quijote en el escenario: desde principios hasta finales del siglo XVII es un loco ridículo que, sin embargo, manifiesta ya aspectos de la riqueza humana del protagonista cervantino; de 1700 a 1750 triunfa la puesta en escena de la novela en toda su magnitud, con verdaderas traducciones en verso de la obra cervantina. Por último, de 1750 a 1800 se observa un don Quijote soggetto, visto como un instrumento de crítica contra la sociedad que como personaje».

Con el libro de Georges Güntert, titulado Cervantes: narrador de un mundo desintegrado, la colección pasó a llamarse Biblioteca Cátedra Miguel de Cervantes y a ser dirigida, más en concreto, por Eduardo Urbina. El libro de Güntert es el resultado de una recopilación de artículos en los que predomina 
el análisis semiológico. Nuevamente estamos ante un libro con intención decididamente crítica, en honor, quizás, del propio Cervantes, al que define como un autor polémico que teorizó una concepción de la literatura en confrontación directa con las teorías poéticas de su tiempo (muy especialmente contra las teorías miméticas). Pero ese pensamiento, claramente enfrentado con el pobre sustrato racional de su época, devuelve la determinación de un Cervantes que contrasta en su global "visión de mundo», donde destacan algunos valores siempre constantes: su preocupación por los aspectos preceptivos y metapoéticos, el carácter irónico y la preferencia por los diálogos como escaparates desde donde mostrar la paradoja del pensamiento humano y sus contradicciones. A partir de ahí Cervantes — en consideración de Güntert- se convierte en un narrador al borde de un mundo abocado al cambio y a la pérdida de sus principios originales: la pluralidad como resultado, la fragmentación de un obsoleto concepto del ser humano y, por tanto, la pérdida de una constatable razón unitaria del ser; es decir, la pérdida de una razonable realidad universalizada en perjuicio de una percepción subjetiva y quebrada de los hechos, del tiempo, del ser. Frente a esa desintegración de la unidad, Cervantes se convierte en el más efectivo narrador de ese proceso de fragmentación de la ideología católica pero, paradójicamente, a través de la uniformidad de su global percepción y plasmación de la realidad mediante la unión de toda su producción en conjunto y no a través de una sola obra en concreto.

El productivo año 2007 se cerró con la publicación de La ficción que no cesa: Paul Auster y Cervantes, de Eduardo Urbina. Es también el resultado de una recopilación de algunos trabajos que, tras la impresión que al autor le produjo la lectura del ensayo de Steven E. Alford (Mirrors of Mandes: Paul Auster's the New York Trilogy), ha venido publicado Urbina, haciendo siempre gala de su capacidad de establecer diálogos abiertos entre textos de épocas y culturas tan diferentes. Observa Urbina la curiosa coincidencia en los dos narradores por ser creadores de una novela «auto-consciente»: «una preocupación constante por elucidar el papel del lenguaje y de la palabra escrita en el devenir ontológico de sus personajes, asiduos lectores, narradores y escritores de historias en busca de identidad y verdades misteriosas». La capacidad de crear siempre un poso de desconfianza ante la realidad nos lleva al simple debate de saber hasta dónde colinda el límite que dirime realidad y ficción, como ocurre en las obras de Auster y Cervantes, si bien desde mecanismos narrativos no muy distintos. Lo curioso es que la tesis que defendía Grilli sobre la disolución de la identidad de don Quijote (podríamos decir, de Don Alonso Quijano), vuelve a surgir, en palabras de Urbina en este caso aunque con un objetivo bien distinto, cuando se refiere a David Quinn, protagonista de la obra de Auster Ciudad de cristal: «en su búsqueda de la verdad se convierte en la negación de su propia realidad». Por tanto, no parecen mal encaminados en sus planteamientos ni el estudio de Grilli ni el de Urbina, aunque el objeto de estudio sea, en líneas singulares, otro.

En el presente 2008 vio la luz editorial el libro de Martha García, La función de los personajes femeninos en Don Quijote de la Mancha y su relevan- 
cia en la narrativa, aunque ya había dado muestras de su buen hacer en las páginas del Anuario, como ya vimos. Pasa por ser un libro inteligente y sin altibajos en su planteamiento, pero solo centrado en las figuras de Marcela, Dorotea, Zoraida y La Duquesa que representan, respectivamente, la retórica (en cuanto elemento de persuasión), la metamorfosis y el travestismo, la otredad y la metateatralidad. Este estudio trata de analizar el complejo entramado de voces femeninas que aparecen en el Quijote y que recorren las distintas esferas sociales y culturales a través de la doblemente marginada voz femenina. Lo curioso es que es Dulcinea, la auténtica quimera femenina que persiste en la obra, la que salva a Don Quijote de su nihilismo: la carencia de ese mundo espiritualizado e idealizado, forjado al calor de una conciencia purista del espíritu, acaba dando un vacío sobrecogedor que el hombre trata de llenar a golpe de irrealidad y de transformación de sus propias frustraciones sociales. Al fin, lo sublime se convierte en trampa mortal de una existencia que, paradójicamente, no existe más allá de su propia naturaleza ficcional. Ciertamente, el amplio y completo libro de Martha García aporta una interesante visión de las relaciones actorales de la célebre novela cervantina, además de hacer una revisión de las diferentes teorías feministas y de la propia literatura precedente para juzgar la consideración de Cervantes en torno a la mujer como personaje novelesco, así tendríamos que la mujer es, en muchos casos, la perspectiva realista que emerge del iluso discurso masculino.

El último libro publicado hasta la fecha por la colección Biblioteca Cátedra Miguel de Cervantes es La puntuación del Quijote (1605 y 1615) de Fidel Sebastián. Su espléndido trabajo está dedicado al análisis y la valoración de cómo un aspecto formal y externo del texto (la puntuación a cargo de los editores) pudo incidir directamente en la presentación del libro a sus lectores, con lo que, de manera directa, marcó su postrera lectura. Además, cabe tener muy presente que el Quijote es una obra que se sitúa en el umbral de los avances de la imprenta, camino de una transición respecto a los usos más o menos estandarizados de los signos de puntuación, junto al abandono de la letra gótica y la nueva utilización de la letra redonda y lo que ello, a nivel tipográfico, significaba. El estudio de Fidel Sebastián aporta una visión poco estudiada hasta la fecha y que, sin duda, ha encontrado su propia obra de referencia para un futuro, pues no solo aporta importante información sobre los usos de la puntuación de las dos ediciones del Quijote, sino que, además, nos deja un legado valiosísimo sobre cómo concebir la publicación, en 1615, de la segunda parte de la novela: marcada por unas condiciones depauperadas, con un pobre papel y tipos gastados que indican ya la decadencia de la imprenta de Juan de la Cuesta, y la prontitud del autor por sacar a la luz pública el texto frente al Quijote de Avellaneda.

Sin duda, el camino emprendido por Jesús G. Maestro y Eduardo Urbina a través de la revista Anuario de Estudios Cervantinos y de la colección Biblioteca Cátedra Miguel de Cervantes, en Editorial Academia del Hispanismo, goza de una importante relevancia dentro de los estudios cervantistas y, con el tiempo, las obras aquí brevemente reseñadas serán todo un referente para los 
nuevos investigadores de la materia: no sólo por la hondura de sus planteamientos, sino porque, al fin, ofrecen una visión mucho más amplia de lo que la obra de Cervantes ha significado para el desarrollo del complejo entramado de la cultura y pensamiento europeos. Además, casi como si constituyese consigna en imprescindible, los textos gozan de una formidable prosa expositiva, nítida, ajena a los formalismos teóricos (si estos no quedan bien justificados de antemano) y a un lenguaje críptico que busca confundir más que exponer e instruir. Muchos - y muy variados - son los frentes cervantinistas que su voluntad y su buen hacer lector han abierto para los que, como nosotros, hemos querido acercarnos a la figura de Miguel de Cervantes, seguros de seguir la buena estela de una tradición crítica que, unas veces - las menosha sabido discernir las pistas de veras de los falsos rastros cervantinos pero que otras - las más - ha llenado nuestros agradecidos listines bibliográficos sin que el sustento de sus palabras difieran, ni siquiera un mínimo, de esa quimérica realidad de la imagen prototípica de Cervantes y su obra. Sin duda, los caminos de la producción del célebre autor barroco son cuantiosos, pero la pregunta es ¿sabremos elegir bien nuestro guía?

En todo caso, y aun sabiendo que resulta completamente imposible realizar una valoración plena y exhaustiva de tantas obras en un breve trabajo como este, hemos pretendido hacer un juicio general de toda una trayectoria editorial, corta pero intensa que, además, se antoja próspera pues recientemente ya ha quedado anunciado el nuevo ganador del III Premio Internacional de Investigación Científica y Crítica Miguel de Cervantes: Antonio Barnés con Yo he leído en Virgilio. La tradición clásica en el Quijote, al que esperan, quienes apuestan por el buen gusto crítico-literario, con los brazos bien abiertos, siempre y cuando el mago Frestón no nos trunque tan ventajoso propósito. 